\title{
RECIENTES ORIENTACIONES DE LA CORTE INTERAMERICANA DE DERECHOS HUMANOS*
}

\author{
Recent trends in Inter-American court \\ of humans rights decisions
}

\author{
Nicolás Pérez Sola \\ Catedrático acreditado de Derecho Constitucional \\ Universidad de Jaén \\ nperez@ujaen.es
}

doi: http://dx.doi.org/10.18543/ed-65(2)-2017pp289-320

Recibido: 26.07.2017

Aceptado: 28.11.2017

\section{Resumen}

La construcción jurisprudencial de la Corte Interamericana de Derechos Humanos presenta interesantes pronunciamientos sobre los derechos de los pueblos indígenas en relación con el uso y disfrute de la tierra con la que mantienen vínculos inmateriales. También revisten enorme interés los pronunciamiento se la Corte sobre las obligaciones de los Estados en materia de desplazados internos. Finalmente, se analizan las Opiniones Consultivas de la Corte que han permitido concretar la responsabilidad en la que pueden incurrir los Estados, en caso de no garantizar los derechos humanos a los migrantes, bien por no haber previsto instrumentos eficaces para su garantía o bien por no haber investigado y sancionado las violaciones que de éstos se hayan producido. La investigación de los desaparecidos constituye una obligación de

* Cómo citar / Citation 'Chicago-Deusto' (Autor-fecha / Author-date / Lista de referencias / Reference list entries): Pérez Sola, Nicolás. 2017. «Recientes orientaciones de la Corte Interamericana de Derechos Humanos». Estudios de Deusto 65, n. ${ }^{\circ}$ 2: 00-00. doi: http://dx.doi.org/10.18543/ed-65(2)-2017pp289-320. 
los Estados que deben participar activamente en el esclarecimiento de los hechos y la averiguación de la verdad.

\title{
Palabras clave
}

Derechos Humanos, corte Interamericana de Derechos Humanos, Derechos de los Pueblos Indígenas, Desplazados, Migrantes, el Derecho a conocer la Verdad.

\begin{abstract}
Inter-American Court of Human Rights has rendered interesting pronouncements on rights of indigenous peoples relating the use and enjoyment of land with which they maintain immaterial ties. The Court's pronouncements on internally displaced persons' state obligations is also of great interest. Finally, we analyze the Advisory Opinions of the Court that have allowed to make States liable whenever they will fail to guarantee the human rights of migrants, either when they do not provide effective means to protect them or when they do not prosecute or sanction violations committed. The inquiry into disappeared constitutes an obligation of States that must actively participate in fact finding and the pursuit for truth.
\end{abstract}

\section{Keywords}

Human Rights, Inter-American Court of Human Rights, Rights of Indigenous Peoples, Displaced Persons, Migrants, Right to know. 
Sumario: 1. Introducción. 2. Pueblos indígenas. 3. Desplazados.

4. MigRANTES. 5. EL DERECHO A CONOCER LA VERDAD.

\section{INTRODUCCIÓN.}

En el afán de edificar una teoría común de los derechos humanos ${ }^{1}$ se ha construido un diálogo de tribunales que, no sólo lo es entre los sistemas regionales de protección de derechos sino entre éstos y los tribunales internos de los Estados parte que los han suscrito. Entre las razones para la interacción entre los tribunales que garantizan derechos humanos aparece, sin duda, la de «su aceptación más generalizada y menos cuestionada « entre los Estado Parte en los sistemas regionales de protección de derechos ${ }^{2}$, dado el valor de los derechos humanos en el ámbito del desarrollo de la personalidad de todos los seres humanos ${ }^{3}$.

Sin ánimo de llevar a cabo una comparación entre ambos sistemas regionales de protección de derechos si puede ser interesante constatar un ámbito de derechos no divergente, pero si con características propias en el sistema interamericano, no siempre con claro referente en el ámbito del sistema de protección del Consejo de Europa ${ }^{4}$. En todo caso cabe destacar la progresiva y constante influencia del derecho internacional en las Constituciones Iberoamericanas, frente a una época anterior en la que los tratados internacionales en materia de derechos humanos habían gozado de una consideración secundaria, hasta el actual «reconocimiento de su nivel jerárquico superior a las normas internas 5 . Es por ello objeto de este presente estudio algunas de

${ }^{1}$ J. García Roca, H. Nogueira Alcalá, R. Bustos Gisbert, «La comunicación entre ambos sistemas y las características del diálogo», El Diálogo entre los Sistemas Europeo y Americano de Derechos Humanos (Civitas-Thomson Reuters, Madrid, 2012), 65.

2 A. Sáiz Arnáiz (Dir.), J. Solanes Mullor, J. E. Roa Roa (Coord.), Diálogos judiciales en el Sistema Interamericano de Derechos Humanos (Tirant lo Blanch/Corte Interamericana de Derechos/Universitat Pompeu Fabra, Valencia, 2017).

${ }^{3}$ «El lenguaje de los derechos refleja la cultura ilustrada de la razón, la dignidad humana y el libre desarrollo de la personalidad», J. García Roca, E. Carmona Cuenca (Eds.), ¿Hacia una globalización de los derechos? El impacto de las sentencias del Tribunal Europeo y de la Corte Interamericana (Instituto de Derecho parlamentario Thomson Reuters Aranzadi, 2017), 73.

${ }^{4}$ F. Salvioli, «Convergencias y divergencias de las jurisdicciones contenciosas en los sistemas europeo e interamericano de protección de derechos humanos», F. SALVIOLI, C. ZANGHI, Jurisprudencia regional comparada de derechos humanos. El Tribunal Europeo y la Corte Interamericana (Sapienza Università di Roma, CEDri, Instituto de Derechos Humanos, Tirant lo Blanch, Valencia, 2013).

${ }^{5}$ H. Fix-Zamudio, «La creciente internacionalización de las Constituciones iberoamericanas, especialmente en la regulación y protección de los derechos humanos», A. 
las más recientes aportaciones de la Corte Interamericana sobre derechos humanos $^{6}$. La lectura de la reciente jurisprudencia de la Corte Interamericana nos permite conocer las nuevas orientaciones de la Corte que, si bien, en algunas materias ya había comenzado años atrás, va confirmando y profundizando en la clarificación del alcance de la protección de los derechos, los titulares de los mismos y las responsabilidades en las que pueden incurrir los Estados en caso de no asumir la protección de aquéllos.

En este contexto, algunos aspectos de la jurisprudencia de la Corte Interamericana despiertan evidente interés por las características que presenta la protección de los derechos de personas vulnerables como los indígenas o los desplazados, pero también los migrantes $\mathrm{y}$, sin duda, constituye un aspecto enormemente relevante la jurisprudencia de la Corte sobre los desaparecidos y el derecho a conocer la verdad. Son sin duda otras dimensiones de la protección de derechos humanos que nos permitirá aproximarnos a estos nuevos desarrollos desde una perspectiva cultural y jurídica diferente ${ }^{7}$, pero en un ámbito de comunicación constante entre ambos sistemas de protección.

\section{PUEBLOS INDÍGENAS.}

La construcción jurisprudencial de la Corte Interamericana de Derechos Humanos (en adelante la Corte) sobre los pueblos indígenas abarca un amplio marco en el que destacan varios ámbitos por sus consecuencias jurídicas. Así junto al reconocimiento de la personalidad jurídica de aquéllos, se ha proclamado de modo indubitado su derecho a la vida, a la integridad personal así como su titularidad de derechos instrumentales como a la tutela judicial efectiva y las garantías judiciales incluso el derecho a usar de los recursos naturales dentro de las tierras que tradicionalmente han poseído.

Un breve recorrido por los recientes pronunciamientos de la Corte nos permitirá conocer los principales desarrollos de la misma sobre los pueblos indígenas, así como las obligaciones de los Estados de respetar y garantizar los derechos de aquéllos sin discriminación, la obligación de adecuar el

Sáiz Arnáiz, E. Ferrer Mac-Gregor (Cords.), Control de convencionalidad, interpretación conforme y diálogo jurisprudencial. Una visión desde América latina y Europa (Porrúa, UNAM, México, 2012), 192.

${ }^{6}$ F. González Morales, Sistema Interamericano de Derechos Humanos (Tirant lo Blanch, Valencia 2013).

7 Se trata de «algunos de los desafíos que enfrenta la protección multinivel en América Latina los cuales, por variados motivos políticos, económicos y sociales, no revisten mayor importancia en otros contextos -como el europeo». R. Ureña, «¿Protección Multinivel de los Derechos Humanos en América Latina? Oportunidades, desafíos y riesgos», G. R. Bandeira Galindo, R. Ureña, A. Torres Pérez, Protección Multinivel de Derechos Humanos, (Universitàt Pompeu Fabra, Barcelona, 2013), 17. 
ordenamiento interno a la Convención Americana sobre Derechos Humanos (en adelante la Convención) en el modo que permita el ejercicio efectivo de los derechos por las comunidades indígenas, así como las medidas de protección que se deben acordar respecto de las personas más vulnerables de estos colectivos, los niños y los ancianos.

El punto de partida lo constituye sin duda el artículo 1.1 de la Convención lo que supone para los Estados la obligación de garantizar de forma efectiva los derechos de las comunidades indígenas en condiciones de igualdad, por lo que aquéllos tendrán que atender a las «características propias que diferencia a los miembros de los pueblos indígenas de la población en general y que conforman su identidad $\iota^{8}$, a la hora de interpretar y aplicar su ordenamiento interno. No se podrá otorgar una protección efectiva sin considerar las condiciones económicas, sociales, su derecho consuetudinario, los valores, usos y costumbres propias de dichas comunidades. Sin duda es el derecho consuetudinario un elemento esencial en la forma de vida de estos pueblos por lo que los Estados deben atender a dichos usos y costumbres en la interpretación que realicen de los derechos contenidos en la Convención cuando afecten a aquéllos.

Es por esta razón que la identidad cultural constituye un elemento principal en el reconocimiento a las comunidades indígenas de un estatuto jurídico en el que la naturaleza colectiva debe ser respetada y en la que destaca, entre otras notas, la «vinculación estrecha» que «guardan con sus tierras, así como con los recursos naturales de los territorios ancestrales y los elementos incorporales que se desprenda de ellos»».

Un primer elemento de análisis lo constituye la concepción de la familia y la regulación de ésta en el contexto de los pueblos indígenas y la incidencia en los mismos de las normas propias del ordenamiento jurídico estatal relativo al derecho de familia. Para la Corte, desde su primer pronunciamiento en esta materia se ha de atender a la diversidad cultural, ya que es evidente que determinados pueblos indígenas ni se rigen por el ordenamiento jurídico estatal en materia de familia y sucesiones ni por tanto se debe atender a dicho ordenamiento para resolver conflictos que se pudieran producir en relación con la propiedad, sucesión, indemnizaciones o restituciones en favor de la comunidad indígena. La Corte se ha manifestado en favor de un entendimiento conforme a la Convención de la estructura social de estas poblaciones atendiendo pues a las peculiaridades de este pueblo en lo relativo a su derecho de familia ${ }^{10}$.

${ }^{8}$ Caso Comunidad Indígena Yakye Axa Vs. Paraguay. Sentencia de 17 de julio de 2005.

9 Caso de las Comunidades Afrodescendientes desplazadas de la Cuenca del Río Cacarica (Operación Génesis) Vs. Colombia. Sentencia de 20 de noviembre de 2013.

${ }^{10}$ Caso Aloeboetoe y Otros Vs. Surinam. Sentencia de 10 de septiembre de 1993. 
Constituye un hito en esta jurisprudencia la resolución de litigios relativos a la propiedad de la tierra en el caso de territorios ancestrales de las comunidades indígenas en los que se sustancia un conflicto vinculado con la propiedad de la tierra. Pues bien, a partir de una interpretación evolutiva de la protección otorgada por la Convención a la propiedad a tenor del artículo 21 de la misma ${ }^{11}$, la Corte ha llevado a cabo una interpretación no restrictiva de la proclamación de derechos que en aquélla se encuentran, como recoge en su artículo $29 \cdot b^{12}$. En concreto se trata de dilucidar la posible titularidad comunal de la propiedad de los pueblos indígenas. A tal efecto la Corte hace hincapié en que «la estrecha relación que los indígenas mantienen con la tiera debe de ser reconocida y comprendida como la base fundamental de sus culturas, su vida espiritual, su integridad y su supervivencia económica. Para las comunidades indígenas la relación con la tierra no es meramente una cuestión de posesión y producción sino un elemento material y espiritual del que deben gozar plenamente, inclusive para preservar su legado cultural y transmitirlo a las generaciones futuras» ${ }^{13}$.

Para la determinación de los daños también es imprescindible atender a los perjuicios inmateriales de la población indígena. Así tras la producción de una masacre se determina la existencia de perjuicios comunitarios o colectivos y no exclusivamente individuales ${ }^{14}$.

Por tanto la concepción de la familia en los pueblos indígenas en todo lo que les puede afectar debe fundamentarse según la Corte en esa «estrecha relación» que los indígenas mantienen con los territorios ancestrales y a partir de este hecho ser reconocida dicha vinculación y comprendida como «la base fundamental de sus culturas, su vida espiritual, su integridad y su supervivencia económica» ${ }^{15}$.

Es por esta concepción familiar que el reconocimiento de la personalidad jurídica choca a veces con la falta de registro e identificación de los miembros pertenecientes a las comunidades indígenas. En este sentido, junto a la personalidad individual de los integrantes de la comunidad la Corte ha incidido en el hecho de que la falta de reconocimiento de la personalidad jurídica colectiva del pueblo «lo convierte en inelegible conforme al derecho interno

\footnotetext{
11 «toda persona tiene derecho al uso y goce de sus bienes».

12 «Ninguna disposición de la presente Convención puede ser interpretada en el sentido de (...) limitar el goce y ejercicio de cualquier derecho o libertad que pueda estar reconocido de acuerdo con las leyes de cualquiera de los Estados partes o de acuerdo con otra convención en que sea parte uno de dichos Estados;»

${ }^{13}$ Caso de la Comunidad (Mayagna Sumo) Awas Tingni Vs. Nicaragua. Sentencia de 31 de agosto de 2001.

14 Caso Masacre Plan Sánchez Vs. Guatemala. Sentencia de 19 de noviembre de 2004.

${ }^{15}$ Caso de la Comunidad Moiwana Vs. Surinam. Sentencia de 15 de junio de 2005.
} 
para recibir el título comunal de sus tierras como comunidad tribal y a tener acceso igualitario a la protección judicial de sus derechos de propiedad» ${ }^{16}$.

En una relación directa con la personalidad jurídica se encuentra el acceso efectivo a la justicia que ha sistematizado la Corte a efectos pedagógicos al señalar que los estándares de protección de derechos han de ser interpretados y aplicados para garantizar su efectividad en los pueblos indígenas teniendo en cuenta no solo el reconocimiento de la personalidad jurídica tanto colectiva como individual, como queda ya comentado, sino con el otorgamiento de capacidad legal que en términos de legitimación les posibilite por sí o por representante, de conformidad con su derecho consuetudinario, interponer acciones en los procedimientos administrativos como en los procesos ante los órganos jurisdiccionales. En resumen, que el acceso a la justicia se realice por los miembros de los pueblos indígenas sin discriminación y de conformidad con su identidad cultural y atendiendo a su posible situación de vulnerabilidad $^{17}$.

En cuanto a la reivindicación de la propiedad de la tierra en numerosas ocasiones se ha suscitado el alcance del derecho a la propiedad de la misma por las comunidades indígenas frente a la ocupación o usurpación de aquélla por terceros. Las circunstancias que concurren en estos conflictos tienen como punto de partida la ausencia de estatuto jurídico de las comunidades indígenas en los Estados y por tanto la imposibilidad de recibir títulos de propiedad de las tierras comunales en nombre de la comunidad, pese a que en numerosas ocasiones desde éstas se hubiesen solicitado con fundamento en su presencia en las tierras desde una época muy anterior. Pues bien, la Corte se ha pronunciado en el sentido de considerar que desde la perspectiva del Derecho Internacional de los Derechos Humanos se debe garantizar «el derecho al territorio comunal que han usado y ocupado tradicionalmente, derivado del uso y ocupación, de larga data, de la tierra y de los recursos necesarios para su subsistencia física y cultural, y asimismo, que el Estado tiene la obligación de adoptar medidas especiales para reconocer, respetar, proteger y garantizar a los integrantes del pueblo Saramaka el derecho de propiedad comunal respecto de dicho territorio»».

Por tanto, la Corte en una interpretación evolutiva del derecho a la propiedad recogido en el artículo 21 de la Convención considera que la aplicación efectiva de este derecho implica no desconocer en el ámbito regional la existencia de otras concepciones del derecho al uso y goce de los bienes atendiendo a criterios culturales, usos y costumbres así como creencias de las distintas comunidades.

${ }^{16}$ Caso del Pueblo Saramaka Vs. Surinam. Sentencia de 28 de noviembre de 2007.

17 Caso Pueblos Kaliña y Lokono Vs. Surinam. Sentencia de 25 de noviembre de 2015. 
Es decir, que las diferentes concepciones del derecho de propiedad no comparten el entendimiento clásico de este derecho, pero no por ello no han de ser objeto de idéntica protección por el citado precepto de la Convención, por el hecho de no centrarse en la titularidad de la persona sino grupal de la comunidad. Frente a estas realidades un entendimiento unívoco del ejercicio de este derecho «significaría hacer ilusoria la protección de tal disposición para millones de personas» ${ }^{18}$.

Además, el entendimiento de la propiedad como uso y disfrute de los terrenos ancestrales ha de ser observado desde la perspectiva de la «conexión intrínseca» de los pueblos indígenas con el territorio, de tal modo que la concepción de la propiedad debe incluir la acepción material, como garantía de su supervivencia física, pero también su acepción cultural, esto es «como desarrollo y continuidad de su cosmovisión», de tal modo que el derecho a la propiedad reconocido por el artículo 21 de la Convención incorpora la obligación de los Estados de «garantizar que puedan continuar viviendo su modo de vida tradicional y que su identidad cultural, estructura social, sistema económico, costumbres, creencias y tradiciones distintivas serán respetadas, garantizadas y protegidas por los Estados $\rangle^{19}$. En ningún caso ha considerado la Corte que una legislación relativa a los pueblos indígenas pueda consistir en una consideración discriminatoria respecto de la población restante del país, antes al contrario, con fundamento en el derecho internacional la Corte apela al «trato desigual a personas en condiciones desiguales al objeto de garantizar su supervivencia de conformidad con sus tradiciones y costumbres $\rangle^{20}$.

Ahora bien, el conjunto de las obligaciones derivadas de aquél precepto para los Estados no se satisfará plenamente en tanto en cuanto no se haya producido la delimitación, demarcación y titulación de las tierras de las comunidades indígenas, único modo de garantizar el principio de seguridad jurídica sobre la titularidad de aquéllas ${ }^{21}$. En caso contrario constituirá una violación «al uso y goce de los bienes de los miembros de dichas comunidades».

Pero para un efectivo sistema de ejercicio del derecho sobre la tierra es preciso con carácter previo que por parte de los Estados se adopten «procedimientos adecuados» en su ordenamiento interno, para «procesar las reivindicaciones de sus tierras, derivado de la obligación general de garantía que establecen los artículos 1 y 2 de la Convención. Los recursos ofrecidos por el

${ }^{18}$ Caso Comunidad Garífuna Triunfo de la Cruz y sus Miembros Vs. Honduras. Sentencia de 8 de octubre de 2015.

${ }^{19}$ Caso de los Pueblos Indígenas Kuna de Madungandí y Emerá de Bayano y sus Miembros Vs. Panamá. Sentencia de 14 de octubre de 2014.

${ }^{20}$ Caso del Pueblo Saramaka Vs. Surinam. Sentencia de 28 de noviembre de 2007.

${ }^{21}$ Caso Pueblos Kaliña y Lokono Vs. Surinam. Sentencia de 25 de noviembre de 2015 . 
Estado deben suponer una posibilidad real para que las comunidades indígenas y tribales puedan defender sus derechos y puedan ejercer el control efectivo de su territorio, sin ninguna interferencia externa». En este sentido y partiendo de la situación de vulnerabilidad en la que se pueden encontrar los pueblos indígenas, el Estado tiene la obligación de posibilitar el acceso a la justicia, así como garantizar que se podrá «lograr la ejecución de las decisiones adoptadas». Por ello y pese a que el territorio sea titulado, será preciso incluso que por el Estado se lleve a cabo el «saneado» de la misma, si estuviese en posesión de terceros. Para la Corte constituye una obligación de oficio del Estado «el deber de sanear» ${ }^{22}$. En el caso de que se haya producido involuntariamente la perdida de las tierras tradiciones por los pueblos indígenas, y éstas hubieren sido transferidas a terceros adquirentes de buena fe, la Corte reconoce «el derecho a solicitar la reivindicación o a obtener otras tierras de igual extensión y calidad» $\rangle^{23}$.

La garantía de la propiedad reviste pues cierta complejidad ya que en múltiples ocasiones la reivindicación de la propiedad por la comunidad indígena y la existencia de propiedad privada particular sobre el mismo territorio deben ser resueltos, por lo que la Corte entiende que lejos de anticipar una solución con carácter general, lo que procede es en cada caso la valoración de la situación de conformidad con los criterios de legalidad, necesidad, proporcionalidad y «el logro de un objetivo legítimo en una sociedad democrática (utilidad pública e interés social), para restringir el derecho de propiedad privada por un lado, o el derecho de las tierras tradicionales, por el otro». En el caso de que atendiendo a razones objetivas, concretas y justificadas no se pueda acordar la devolución del territorio tradicional a las comunidades indígenas corresponderá al Estado llevar a cabo el ofrecimiento de «tierras alternativas de igual o mayor extensión y calidad, el pago de una justa indemnización o ambos y de manera consensuada con los pueblos interesados $\gg\rangle^{24}$.

Ahora bien, para la resolución de los conflictos que se puedan presentar para la recuperación de tierras por los pueblos indígenas la Corte ha fijado una serie de criterios a seguir. En primer lugar, a la posesión tradicional de los indígenas sobre sus tierras se le confiere efectos equivalentes al título de pleno dominio que reconocen los ordenamientos jurídicos internos. Por tanto la posesión tradicional de esos territorios posibilita la exigencia por los

${ }^{22}$ Caso Comunidad Garífuna de Punta Piedra y sus Miembros Vs. Honduras. Sentencia de 8 de octubre de 2015.

${ }^{23}$ Caso Pueblos Kaliña y Lokono Vs. Surinam. Sentencia de 25 de noviembre de 2015.

${ }^{24}$ Caso Pueblos Kaliña y Lokono Vs. Surinam. Sentencia de 25 de noviembre de 2015. 
indígenas del reconocimiento legal de la propiedad de los mismos y la correspondiente inscripción registral. En segundo lugar, corresponde al Estado llevar a cabo la delimitación, demarcación y el otorgamiento del título colectivo de las tierras a los miembros de las comunidades indígenas. Por último, en el caso de pérdida de la posesión de las tierras por causa ajena a la voluntad de las comunidades indígenas, conservarán el derecho de propiedad sobre ellas salvo adquisición de aquéllas por terceros de buena fe, si bien podrán reivindicarlas o interesar la obtención de otras tierras «de igual extensión y calidad $\gg^{25}$.

En todo caso, la recuperación de las tierras tradicionales ha sido objeto también de estudio por la Corte, que ha establecido «que la base espiritual y material de la identidad de los pueblos indígenas se sustenta principalmente en su relación única con sus tierras tradicionales, por lo que mientras esa relación exista, el derecho a la reivindicación de dichas tierras permanecerá vigente. Si esta relación hubiera dejado de existir, también se extinguiría ese derecho». Si bien, para poder constatar la pervivencia de este vínculo entre la población indígena y sus tierras tradicionales, la Corte ha establecido que no cabe un entendimiento único de esta conexión y por tanto habrá que atender a las características propias de cada pueblo indígena del que se trate y las circunstancias concretas en que se encuentre, así como que esta relación sea efectiva, señalándose como manifestación de ella «el uso o presencia tradicional, a través de lazos espirituales o ceremoniales, asentamientos o cultivos esporádicos; caza, pesca o recolección estacional o nómada; uso de recursos naturales ligados a sus costumbres, y cualquier otro elemento característico de su cultura», sin que por causas ajenas a su voluntad se vean impedidos de llevar a cabo tales actividades que acreditan «la persistencia de la relación con sus tierras tradicionales ${ }^{26}$.

Otro aspecto sobre el que ha tenido ocasión la Corte de pronunciarse es respecto del alcance del artículo 21 de la Convención en su aplicación a los pueblos indígenas en orden al alcance del derecho a la propiedad tanto del suelo como del subsuelo, a efectos de la garantía de sus territorios ancestrales. En este sentido se ha dirimido si el uso y goce debiera limitarse a la superficie y recursos naturales del territorio, en la medida en que se garantiza su existencia y supervivencia en las formas tradicionales de vida de éstos, o si debe alcanzar también al subsuelo y los recursos que se encuentran bajo dicha superficie. En suma, se está abordando la cuestión de los límites en el alcance de la propiedad respecto de la exploración y explotación de los

${ }^{25}$ Caso comunidad Indígena Xákmok Kásek Vs. Paraguay. Sentencia de 24 de agosto de 2010 .

${ }^{26}$ Caso comunidad Indígena Xákmok Kásek Vs. Paraguay. Sentencia de 24 de agosto de 2010 . 
recursos naturales superficiales (agua, madera) y los que se encuentran en el interior de la tierra (mineros). En respuesta a esta cuestión la Corte ha señalado la necesidad de proteger las tierras y los recursos de los que se han valido tradicionalmente para "prevenir su extinción como pueblo» y garantizar «que podrán continuar viviendo su modo de vida tradicional y su identidad cultural».

Ahora bien, la Corte no sustenta una interpretación absoluta del artículo 21 de la Convención de forma tal que «no permite una interpretación así de restrictiva», sino que este derecho está sujeto a ciertos límites y por tanto, procederá la realización de exploración y explotación de proyectos con un condicionado que se resume en la participación de la población indígena en los proyectos, la participación en los beneficios que se deriven de dichos proyectos y el no otorgamiento de concesión alguna sin el previo estudio de impacto social y ambiental ${ }^{27}$. A la hora de llevar a cabo los referidos estudios de impacto ambiental se debe atender a las tradiciones de los pueblos indígenas y corresponderá a los Estados verificar que en la realización de aquéllos «coincide con su deber de garantizar la efectiva participación del pueblo indígena $»^{28}$. Es en este sentido que se ha afirmado que constituye una obligación "convencional», pero también un principio de derecho internacional, que los Estados cuenten con «mecanismos adecuados y efectivos para garantizar el proceso de consulta en estos casos, sin perjuicio de que pueda ser precisada en ley» ${ }^{29}$, en todo lo que les pueda afectar en sus derechos y especialmente a la propiedad comunal de conformidad con sus valores culturales, costumbres y forma de organización propia. En caso contrario se puede derivar responsabilidad internacional del Estado.

Respecto de las características que ha de reunir la participación de las comunidades indígenas en aquellos proyectos que les puedan afectar la Corte se ha manifestado en un doble sentido. Desde el punto de vista cronológico, se apuesta por una intervención y participación desde la fase inicial de elaboración o planificación de los proyectos que les afecten, al objeto de que puedan opinar e «influir» en la posterior toma de decisiones. En cuanto a la finalidad de estos procesos de diálogo y consulta, la Corte ha señalado que se deben llevar a cabo con carácter previo, de buena fe, con la finalidad de llegar a un acuerdo, de forma «adecuada, accesible e informada $»^{30}$.

${ }^{27}$ Caso del Pueblo Saramaka Vs. Surinam. Sentencia de 28 de noviembre de 2007.

${ }^{28}$ Caso Pueblos Kaliña y Lokono Vs. Surinam. Sentencia de 25 de noviembre de 2015.

${ }^{29}$ Caso Comunidad Garífuna de Punta de Piedra y sus Miembros Vs. Honduras. Sentencia de 8 de octubre de 2015.

${ }^{30}$ Caso Comunidad Garífuna de Punta de Piedra y sus Miembros Vs. Honduras. Sentencia de 8 de octubre de 2015 
No desconoce, por otro lado la Corte, que los pueblos indígenas «pueden desempeñar un rol relevante en la conservación de la naturaleza, dado que ciertos usos tradicionales conllevan prácticas de sustentabilidad y se consideran fundamentales para la eficacia de las estrategias de conservación. Por ello, el respeto de los derechos de los pueblos indígenas, puede redundar positivamente en la conservación del medio ambiente ${ }^{31}$.

Con alcance diferente la Corte se ha hecho eco de la titularidad de derechos políticos por parte de los integrantes de las comunidades indígenas, sin que las exigencias de la normativa electoral concreta pueda excluir del ejercicio de tal derecho en su esfera activa para presentarse como candidato a quienes no estén encuadrados en partido político, coaliciones u otras candidaturas colectivas fruto de agrupación de votantes, sin perjuicio de la vulneración del derecho a la participación en condiciones igualdad en las elecciones $^{32}$.

Con carácter general conviene recordar que el art. 1.1 de la Convención Americana proscribe la discriminación, tanto con carácter general, como respecto a determinadas consideraciones o características de la persona como la etnia $^{33}$. Es por ello que los Estados tienen una obligación de respetar y garantizar los derechos sin discriminación de tal modo que deberán otorgar una protección efectiva atendiendo a las características, peculiaridades, derecho consuetudinario o especial vulnerabilidad de los miembros de las comunidades indígenas, debiendo abstenerse de cualquier acción que de modo directo o indirecto pueda crear situaciones de discriminación ${ }^{34}$.

Finalmente presenta interés el alcance de las resoluciones de la Corte relativas a la reparación a las poblaciones indígenas de los perjuicios a ellas causados y violaciones de sus derechos. Así entre las medidas de satisfacción y garantía de no repetición se encuentra el respeto a los restos mortales, el entierro de los mismos según las costumbres de la comunidad así como la obligación de investigar, juzgar y sancionar a los culpables. Además, el Estado condenado por la Corte deberá realizar un acto público de reconocimiento de responsabilidad de conformidad con las costumbres y el idioma de la comunidad indígena, y cuando fuere preciso, diseñar e implementar un programa para la recuperación de la memoria colectiva y el mantenimiento de la cultura ${ }^{35}$. A tal efecto incluso se podrá constituir un Fondo ante la desposesión del territorio y los daños causados al mismo para llevar a cabo el desarrollo de proyectos

${ }^{31}$ Caso Pueblos Kaliña y Lokono Vs. Surinam. Sentencia de 25 de noviembre de 2015.

${ }^{32}$ Caso Chitay Nech y otros Vs. Guatemala. Sentencia de 25 de mayo de 2010.

${ }_{33}$ Caso Norín Catrimán y otros Vs. Chile. Sentencia de 29 de mayo de 2014.

${ }^{34}$ Caso Rosendo Cantú y otra Vs. México. Sentencia de 31 de agosto de 2010.

${ }^{35}$ Caso Masacre de Río Negro Vs. Guatemala. Sentencia de 4 de septiembre de 2012. 
cuyo objetivo sea el incremento de la productividad agrícola, la mejora de las infraestructuras de la Comunidad a tenor de sus necesidades, la restauración de zonas desforestadas y cualquier otro objetivo que repercuta en beneficio de la Comunidad ${ }^{36}$.

$\mathrm{Al}$ objeto de asegurar el derecho de propiedad sobre las tierras ancestrales de las poblaciones indígenas se preverá en la sentencia la devolución de las mismas y su uso efectivo si este fuese posible, incluso acudiendo a la vía de expropiación y procediendo, en su caso, al saneamiento que, como ya se indicó, corresponderá al Estado ejercerlo de oficio y con extrema diligencia. Cuando no sea posible la restitución la Corte puede imponer al Estado la obligación de llevar a cabo el ofrecimiento de tierras dentro del territorio tradicional de sus ancestros de modo consensuado con los miembros de la Comunidad $^{37}$. De forma complementaria se puede acordar en la sentencia llevar a cabo la modificación de la legislación interna al objeto de incorporar al sistema administrativo y jurisdiccional «un sistema eficaz de reclamación de tierras» al objeto de hacer efectivo el ejercicio del derecho a la propiedad de las comunidades indígenas con la garantía de que en caso de conflicto por la propiedad de las tierras por particulares y comunidades indígenas será un órgano jurisdiccional el que resuelva dicho litigio ${ }^{38}$.

\section{DESPLAZADOS INTERNOS}

La existencia de conflictos internos de distinta naturaleza que hayan podido existir en el propio Estado ha ocasionado el desplazamiento de población que, fuera de su entorno habitual, puede encontrarse en una situación de vulnerabilidad. Esta realidad tiene que ser igualmente atendida, no sólo por los órganos jurisdiccionales en la interpretación y aplicación del ordenamiento jurídico, sino por el resto de las instituciones del Estado para posibilitar una efectiva integración de los mismos en su nuevo entorno.

Una aproximación conceptual al desplazamiento se puede realizar desde pronunciamientos jurisprudenciales como el de la Corte Constitucional Colombiana en el sentido de que «no es el registro formal ante los entes gubernamentales el que le da el carácter de desplazado a un individuo sino el

${ }^{36}$ Caso Comunidad Garífuna Triunfo de la Cruz y sus Miembros Vs. Honduras. Sentencia de 8 de octubre de 2015.

${ }^{37}$ Caso Comunidad Indígena Xakmok Kásek Vs. Paraguay. Sentencia de 24 de agosto de 2010.

${ }^{38}$ Caso Comunidad Indígena Xakmok Kásek Vs. Paraguay. Sentencia de 24 de agosto de 2010 . 
mero hecho de haberse visto compelido a abandonar el lugar de residencia habitual $»^{39}$.

La definición de los desplazados internos se ha formulado en el entendimiento de éstos como «las personas o grupos de personas que se han visto forzadas u obligadas a escapar o huir de su hogar o de su lugar de residencia habitual, en particular como resultado o para evitar los efectos de un conflicto armado, de situaciones de violencia generalizada, de violaciones de los derechos humanos (...) y que no han cruzado una frontera estatal internacionalmente reconocida». Además los desplazados sufren desarraigo cultural, desarticulación social, empobrecimiento y un considerable deterioro en sus condiciones de vida. Es en este sentido en el que el desplazamiento forzado es considerado como una violación múltiple de derechos humanos que se traduce en una falta de atención así como un estado de carencia que puede afectar «el derecho de los familiares de las víctimas a una vida digna, en relación con el incumplimiento de las obligaciones de respeto y garantía de los derechos consagrados en esas normas».

Respecto de los desplazados internos cabe decir que éstos gozan de la protección de la Convención para circular libremente y establecer su residencia. El reconocimiento del derecho de circulación genera una obligación positiva a los Estados que deben adoptar las medidas que permitan la efectividad de este derecho, es por ello que si el Estado no ha garantizado en modo suficiente el ejercicio de este derecho frente a la existencia de amenazas que provengan de actores no estatales que le impidan fijar libremente su residencia y permanecer en la misma, se puede declarar la vulneración de este derecho por el Estado ${ }^{40}$. De tal modo que una interpretación amplia del artículo 22 de la Convención supone el reconocimiento de un derecho a no ser desplazado de forma interna dentro del propio país ${ }^{41}$.

Ahora bien, cualquier restricción a este derecho tiene un carácter excepcional y deberá estar expresamente previsto en la ley «en la medida indispensable en una sociedad democrática para la prevención de infracciones penales o bien para la protección de la seguridad nacional, el orden público o la protección de los derechos y libertades (artículo 22.2 $2^{42}$ ). Esta restricción se podrá acordar para «zonas determinadas, por razones de interés público». En

${ }^{39}$ Sentencia T025 de 22 de enero de 2004, emitida por la Sala Tercera de Revisión de la Corte constitucional.

${ }^{40}$ Caso Chitay Nech y otros Vs. Guatemala. Sentencia de 25 de mayo de 2010.

${ }^{41}$ Caso Masacre de Mapiripán Vs. Colombia. Sentencia de 15 de septiembre de 2005. Caso de las Masacres de Ituango Vs. Colombia. Sentencia de 1 de julio de 2006.

42 «Toda persona que se halle legalmente en el territorio de un Estado tiene derecho a circular por el mismo y a residir en él con sujeción a las disposiciones legales. 2. Toda persona tiene derecho a salir libremente de cualquier país, inclusive del propio». 
todo caso, como ha recogido la jurisprudencia de la Corte Interamericana cuando las restricciones a la libertad de circulación se encuentren previstas en la ley, serán objeto de interpretación restrictiva ${ }^{43}$. La incidencia de estas restricciones será expresamente intensa cuando en el ámbito del derecho penal se acuerde como medida cautelar y habrá de responder su adopción a la presunción de inocencia, así como a la proporcionalidad en la adopción de dicha medida.

En efecto, la Corte ha asumido una interpretación del citado artículo 22 de la Convención de conformidad con los Principios Rectores de los Desplazamientos internos de las Naciones Unidas en el sentido de otorgar dicha protección a quienes sufren este desplazamiento. La relevancia de los Principios Rectores de los Desplazamientos Internos emitida en 1998 por el Representante del Secretario General de las Naciones Unidas ha sido destacada por la Corte al objeto de definir el contenido y alcance del artículo 22 de la Convención, sin perjuicio de atender igualmente a las regulaciones que de los desplazados se encuentran en el Protocolo II a los Convenios de Ginebra de 1949. Con especial atención se ha de observar el artículo 17 del citado Protocolo que contiene la prohibición de ordenar el desplazamiento de la población por razones relacionadas con un conflicto. La única excepción a esta regla será cuando existan razones de seguridad de las personas civiles o razones militares imperiosas, en cuyo caso, se deberán adoptar «todas las medidas posibles para la población civil sea acogida en condiciones satisfactorias de alojamiento, salubridad, higiene, seguridad y alimentación» ${ }^{44}$.

El desplazamiento forzado puede suponer una violación múltiple de derechos reconocidos en la Convención, en la media en que se puede atentar contra el derecho a la vida (art. 4) a la integridad personal (art. 5) (5) $^{45}$ la libertad personal (art. 7) ${ }^{46}$. De igual modo, con la destrucción del ganado o de la vivienda se puede estar violando el derecho a la propiedad (art. 21) $)^{47}$, el respeto a la vida privada y al domicilio (art. 11.2).

No obstante se ha de reparar en la dificultad en la identificación de las víctimas en los casos de desplazamiento forzado y la necesidad de considerar las particularidades del caso para dicho proceso. Así la Corte ha afirmado que ante «las complejidades y dificultades para identificar plenamente a todas las

${ }^{43}$ Caso Ricardo Canese Vs. Paraguay. Sentencia de 31 de agosto de 2004.

${ }^{44}$ Caso de las Masacres de Ituango Vs. Colombia. Sentencia de 1 de julio de 2006.

${ }^{45}$ Caso Defensor de Derechos Humanos y otros Vs. Guatemala. Sentencia de 28 de agosto de 2014.

46 Ibídem.

${ }^{47}$ Ibídem. 
presuntas víctimas, en las circunstancias propias del caso», se hace necesario «adoptar criterios flexibles que atiendan a las particularidades» del mismo ${ }^{48}$.

Hemos insistido ya en la situación de debilidad, vulnerabilidad e indefensión en la que se encuentran quienes como consecuencia del desplazamiento en contra de su voluntad han debido abandonar enseres, propiedades, viviendas y quedan sujetos durante el desplazamiento a amenazas de todo tipo y persecuciones. En este contexto de profundo desarraigo por la extracción generalmente rural de la población que sufre el desplazamiento la vulnerabilidad se ve incrementada en el caso de mujeres, menores y personas de la tercera edad. La jurisprudencia de la Corte se ha hecho eco de esta situación de discriminación e indefensión, señalando que corresponde a los Estados la obligación de adoptar cuantas medidas sean pertinentes al objeto de paliar la situación en la que se puede encontrar el desplazado con riesgo de sufrir la vulneración de diversos derechos humanos.

En este sentido, las obligaciones de los Estados alcanzan también a la necesaria investigación de los casos de violación de los derechos de los desplazados, así como a la adopción de medidas eficaces para garantizar el regreso a su residencia habitual o, en su caso, un reasentamiento voluntario en otro lugar del país. La Corte ha incidido en la necesidad de configurar un estatuto jurídico del desplazado con precisión de los derechos individuales y del colectivo, así como las obligaciones de autoridades y poderes públicos respecto de ellos. Es por estas razones que se debe hacer hincapié en la necesidad de configurar un estatuto jurídico del desplazado con precisión de los derechos individuales y del colectivo, así como las obligaciones de autoridades y poderes públicos respecto de ellos.

Las circunstancias personales se agravan considerablemente cuando el desplazamiento forzado afecta a poblaciones indígenas, dado su especial vínculo con el territorio, como se ha señalado con anterioridad, con connotaciones culturales y religiosas ${ }^{49}$. El choque que se puede producir entre los desplazados y la población del lugar de asentamiento puede generar conflictos al entrar en contacto con otra cultura, formas de vida e incluso idioma. Igualmente no se puede olvidar el fenómeno de rechazo que se puede producir de los desplazados por parte de la población del lugar.

La Corte ha incorporado en su fundamentación jurídica los Principios Rectores de los Desplazamientos Internos con el objetivo de conseguir la mejora de las condiciones de los desplazados especialmente por su impacto en el ámbito familiar como en el conjunto de la sociedad, dada la precariedad en la que sume a los mismos frente al acceso a la alimentación, medicinas y

${ }^{48}$ Caso de las Comunidades Afrodescendientes Desplazadas de la Cuenca del Río Cacarica (Operación Génesis) Vs. Colombia. Sentencia de 20 de noviembre de 2013.

49 Caso Comunidad Indígena Yake Vs. Paraguay. Sentencia de 17 de junio de 2005. 
la exposición a las diversas formas de violencia ${ }^{50}$. Es por ello que con la incorporación de dichos Principios Rectores a la jurisprudencia de la Corte se persigue generar una serie de obligaciones para los gobiernos, las organizaciones no gubernamentales así como las de ámbito internacional, pese a carecer de obligatoriedad jurídica aquéllos.

En algunas ocasiones dado que el desplazamiento ha tenido lugar como consecuencia de pertenecer a minorías, etnias o creencias religiosas los supuestos de discriminación han podido desdibujar su condición de ciudadanos de pleno derecho en el Estado del que son miembros. Corresponde a los Estados a tenor de lo señalado por la Corte, la obligación de garantizar el derecho a la vida, la dignidad, la libertad y la seguridad de los afectados por el desplazamiento. Incluso en el colectivo de desplazados se deben identificar las personas con «necesidades especiales» que requerirán un tratamiento más adecuado a dichas necesidades. En este colectivo tienen cabida los niños, los menores no acompañados, las mujeres y en su caso las embarazadas o con hijos pequeños, discapacitados y ancianos.

A veces, frente a los desplazados se detecta el abandono de sus responsabilidades por parte del Estado y las autoridades, con dejación de sus obligaciones y responsabilidades. Es por este motivo que la Corte ha recordado también a los Estados la responsabilidad de los mismos y la obligación de evitar, prevenir o minimizar las consecuencias de los desplazamientos internos. De tal modo que corresponde a las autoridades detectar previamente los riesgos de desplazamientos, en su caso valorar opciones que eviten el desplazamiento y en la medida en que esto sea posible, llevar a cabo consultas a las poblaciones que se verían afectadas por dicho desplazamiento. Además, la actitud de los gobiernos no puede ser proclive a dichos desplazamientos, bien como consecuencia de desastres naturales o como consecuencia de la ejecución de infraestructuras o proyectos de desarrollo, debiendo de abandonar cualquier actitud de arbitrariedad incluso en la reubicación de los colectivos desplazados por estas causas ${ }^{51}$. Sin perder de vista nunca que estos desplazamientos deben ser en todo caso temporales con la opción real del retorno con plenitud de derechos y sin riesgos si estos se producen.

Como es obvio, la protección vinculada a la dignidad personal debe siempre estar garantizada frente a la tortura, trato inhumano y degradante, así como frente a la agresión sexual, violencia o trabajo forzado de niños. La situación de los desplazados tampoco se puede ver agravada con la restricción en su libertad con detención arbitraria, internamiento o confinamiento,

${ }^{50}$ Caso de las Comunidades Afrodescendientes Desplazadas de la Cuenca del Río Cacarica (Operación Génesis) Vs. Colombia. Sentencia de 20 de noviembre de 2013.

${ }^{51}$ Caso de la Masacre de Mapiripán Vs. Colombia. Sentencia de 15 de septiembre de 2005. 
por lo que se les debe garantizar libertad de movimientos en los lugares en los que hayan sido desplazados. Así mismo, la Corte ha recordado que existe una prohibición absoluta en derecho internacional sobre el reclutamiento militar forzado de menores, tanto las Convenciones de Ginebra de Derecho Humanitario como la Convención sobre los Derechos del Niño contienen una prohibición absoluta respecto de los menores de quince años y la adopción de todo tipo de cautelas en relación con los que aún no hayan alcanzado los dieciocho años.

Desde la Corte se ha hecho hincapié en como en estos Principios Rectores se reitera la preservación de la unidad familiar ${ }^{52}$ pese a los desplazamientos, por lo que en caso de no haberse podido preservar por parte de las autoridades, se llevarán a cabo las pesquisas pertinentes para la localización del paradero de los familiares desaparecidos, así como facilitar la reunificación familiar una vez se haya producido dicha localización. En los programas que desarrollen las Administraciones correspondientes que afecten a los desplazamientos se debe procurar que aquéllas permanezcan unidas.

Los desplazados también son titulares de derechos sociales, especialmente en orden a su subsistencia con dignidad, al acceso a alimentos y agua potable así como a los servicios médicos y sanitarios esenciales para preservar su salud, no sólo física sino también mental, ya que los conflictos suelen generar un alto nivel de estrés postraumático en muchas de las personas desplazadas.

En este ámbito socioeconómico resulta igualmente necesario garantizar el derecho al trabajo de la población desplazada, al menos cuando haya evidencia de que el retorno no se va a producir de modo inmediato. De esta forma se podrá contribuir a la economía familiar y no depender exclusivamente de la ayuda humanitaria. En el mismo sentido, por las autoridades se debe velar por la conservación de las propiedades y bienes de los desplazados frente al pillaje y actos de apropiación indebida de las mismas. En caso de que se produzca el retorno al lugar de residencia original también las autoridades deberán velar por la restitución, en su caso, de los bienes ilícitamente apropiados, así como la resolución de controversias sobre derechos de propiedad litigiosa, tras los conflictos que originaron el desplazamiento.

Respecto a la escolarización gratuita de los menores desplazados ésta debe constituir un objetivo prioritario de las autoridades, sin perjuicio de que se pueda facilitar el acceso a la educación en el resto de los niveles educativos con respeto a su identidad cultural, lingüística o religiosa.

${ }^{52}$ Caso Defensor de Derechos Humanos y otros Vs. Guatemala. Sentencia de 28 de agosto de 2014 . 
Una vez que hayan desaparecido las causas que motivaron el desplazamiento por las autoridades se debe garantizar el retorno al lugar de origen ${ }^{53}$, la elección de una nueva residencia se realizará siempre de forma voluntaria en condiciones de seguridad y dignidad como ciudadanos de pleno derecho del Estado ${ }^{54}$, aunque se debe incidir en el dialogo y las consultas entre desplazados y población residente en áreas de retorno o reasentamiento para perfeccionar los procedimientos que permitan el reasentamiento más completo.

La restauración de bienes, derechos, posesiones una vez realizado el retorno según la Corte debe estar plenamente garantizada. Incluso por las autoridades se podrá adoptar instrumentos de resolución pacífica de conflictos jurídicos que, en caso de la imposibilidad de la restauración de la propiedad, deberá acudir a fórmulas de reparación indemnizatoria por las pérdidas sufridas.

En el mismo sentido, la identidad de las personas desplazadas debe quedar garantizada a través de los respectivos documentos que la acrediten que, en el caso de su destrucción o desaparición, deben ser expedidos nuevamente por las autoridades. La titularidad de la documentación debe permitir el ejercicio pleno de los derechos de los desplazados, incluidos los derechos políticos y de participación, en condiciones de igualdad con la población del lugar donde se hayan asentado, al objeto de su participación en plenitud en los asuntos de la comunidad.

En el caso de que como consecuencia de los conflictos y sucesos que motivaron el desplazamiento se haya producido una alteración significativa del medio originario, procederá en su caso la realización de estudios de impacto ambiental previos a acordar los procesos de reasentamiento, incluso llevando a cabo la planificación de la reparación ambiental, cuando ésta sea necesaria con carácter previo al retorno de los desplazados

\section{MIGRANTES}

Frente a la escasa regulación de la extranjería en sus distintas manifestaciones en los instrumentos internacionales de derechos humanos, ha sido la Corte la que con sus Opiniones Consultivas y jurisprudencia ha concretado la responsabilidad en la que pueden incurrir los Estados, en caso de no garantizar los derechos humanos, bien por no haber previsto instrumentos eficaces para su garantía o bien por no haber investigado y sancionado las violaciones que de éstos se hayan producido. Así el estatuto jurídico de las personas que se encuentran en otro Estado del que no son nacionales comienza a desentrañarse a partir de la obligación real y efectiva contenida en el art. 1 de la

\footnotetext{
${ }^{53}$ Caso de las Masacres de Ituango Vs. Colombia. Sentencia de 1 de julio de 2006.

${ }^{54}$ Caso de la Comunidad Moiwana Vs. Surinam. Sentencia de 15 de junio de 2005.
} 
Convención Americana, de «respetar los derechos y libertades» en ella reconocidos y «a garantizar su libre y pleno ejercicio a toda persona que esté sujeta a su jurisdicción». Por tanto esta obligación de los Estados alcanza a la generalidad de las personas que por encontrarse en el territorio de aquéllos quedan sujetos a su jurisdicción, «sin discriminación alguna» entre otras razones por el «origen nacional» de éstas.

En aplicación de este precepto la Corte ha destacado varias consecuencias: en primer lugar, de dicho enunciado no sólo surge la obligación de respeto sino que genera en los Estados la necesidad de desplegar acciones positivas que posibiliten el ejercicio efectivo de una serie de derechos reconocidos en aquélla. En segundo lugar, la obligación de respeto de los derechos no se circunscribe a la relación de los Estados con los particulares, sino que trasciende también a las relaciones entre particulares, por lo que los Estados han de adoptar las medidas pertinentes para garantizar los derechos también en estas relaciones. En tercer lugar, esta obligación debe ser completada con la prohibición general de la discriminación sin justificación objetiva y razonable ${ }^{55}$, que se proclama en el artículo 24 de la misma ${ }^{56}$, ya que la igualdad de todas las personas ante la ley conlleva «igual protección ante la ley».

De conformidad con lo preceptuado en el artículo 1 de la Convención Americana por lo que respecta al migrante en situación regular en otro Estado, la Corte ha señalado que se le debe garantizar el derecho a la libre circulación y la libertad de elegir una residencia, pues ambos constituyen un requisito indispensable para el libre desarrollo de la persona. Las garantías que alcanzan al migrante en esta situación incluyen el acceso y ejercicio a los derechos sociales, económicos y culturales, sin que puedan sufrir discriminación por razón de origen, raza, religión, etc.

En este ámbito es de enorme relevancia el contenido de la Opinión Consultiva OC-21/14. Si bien es cierto que con anterioridad ya se había producido alguna aportación de la Corte en esta materia, con la opinión Consultiva OC-21/14 se produce un amplio reconocimiento de los derechos de los migrantes y las consiguientes obligaciones de los Estados en distintas esferas de la migración: el ámbito del trabajo, el de los menores no acompañados, la restricción de derechos, etc. Al respecto, hemos de señalar, aun reconociendo la competencia de los Estados en ejercicio de su soberanía para acordar las políticas migratorias que consideren pertinentes, que éstas en todo caso han de observar el respeto y la garantía de los derechos humanos ${ }^{57}$. Es por ello

${ }^{55}$ Caso Yatama Vs. Nicaragua. Sentencia de 23 de junio de 2005.

56 «Igualdad ante la Ley. Todas las personas son iguales ante la ley. En consecuencia, tienen derecho, sin discriminación, a igual protección de la ley».

${ }^{57}$ Opinión Consultiva OC-18/03. Condición jurídica y derechos de los migrantes indocumentados. Decisión de 17 de septiembre de 2003. 
que se podrán establecer precisas normas relativas al ingreso en el país, en la permanencia en el mismo o, en su caso, las circunstancias que han de concurrir para el abandono del territorio del Estado dentro del respeto a la dignidad de las personas. Por tanto, ante incumplimientos del ordenamiento jurídico por los migrantes podrán los Estados adoptar medidas pertinentes siempre con respeto al ejercicio y garantía de los derechos humanos ${ }^{58}$.

Igualmente corresponderá a los Estados fijar los criterios relativos al otorgamiento o denegación de permisos de trabajo ya tengan estos carácter general o para la realización de labores determinadas, pero han de tomar cuantas medidas sean necesarias para asegurar que no se produzca discriminación alguna atendiendo a las características personales del migrante trabajador, con observancia estricta de la adecuación de las características de éste para la actividad laboral a desempeñar ${ }^{59}$.

En orden a la realización de actividad laboral por los migrantes, la Corte hace hincapié, en las reglas que rigen en el marco de las relaciones laborales entre trabajadores migrantes y empleadores, ya que su incumplimiento puede acarrear responsabilidad internacional del Estado. En primer lugar, los Estados tienen el deber de garantizar los derechos de los trabajadores y, en todo caso, prevalecer la prohibición del trabajo forzado ${ }^{60}$ así como del trabajo infantil. En segundo lugar, la responsabilidad de los Estados alcanza a garantizar el ejercicio de derechos vinculados a la actividad laboral como la libertad de asociación y libertad sindical, negociación colectiva, salario justo por trabajo realizado, seguridad social, garantías judiciales y administrativas, duración de jornada razonable y condiciones laborales adecuadas (seguridad e higiene), descanso e indemnización. Finalmente, los Estados podrán incurrir en responsabilidad «cuando toleran acciones y prácticas de terceros que perjudican a los trabajadores migrantes, ya sea porque no les reconocen los mismos derechos que a los trabajadores nacionales o porque les reconocen los mismos derechos pero con algún tipo de discriminación ${ }^{61}$.

Los extranjeros que se encuentren de forma irregular en el territorio de otro Estado solo podrán ser expulsados de él en cumplimiento de una decisión adoptada de conformidad con la ley (artículo 22.4). Esta prohibición de alcance general se matiza, de un lado, con carácter restrictivo aún más en

${ }^{58}$ Opinión Consultiva OC-18/03. Condición jurídica y derechos de los migrantes indocumentados. Decisión de 17 de septiembre de 2003.

${ }^{59}$ Caso Nadege Dorzema y otros Vs. República Dominicana. Sentencia de 24 de octubre de 2012.

${ }^{60}$ Caso de las Masacres de Ituango. Sentencia de 1 de julio de 2006.

${ }^{61}$ Opinión consultiva OC-21/14. Derechos y garantías de niñas y niños en el contexto de la migración y/o en necesidad de protección internacional. Decisión de 19 de agosto de 2014. 
relación con la expulsión a otro país en el que corra riesgo «su derecho a la vida o a la libertad personal» por causa de raza, nacionalidad, religión, condición social o por sus opiniones políticas. Por otra parte, esta prohibición alcanza en todo caso a llevar a cabo expulsiones colectivas de extranjeros ${ }^{62}$.

En este contexto, el acceso a la Administración de justicia reviste al menos dos ámbitos específicos de desarrollo que han de ser observados atendiendo a su condición de no nacional del Estado en el que se encuentran frente a sus instituciones, pero también y en segundo lugar, por su condición de potencial justiciable o víctima de hecho delictivo.

La persona migrante, en tanto que no nacional del país en el que se encuentra, dicha condición puede afectarle directamente a su situación y, por ello, la necesidad de acudir a la Administración pertinente para obtener alguna fórmula de regulación, aun cuando ésta sea provisional, de su presencia en el país ${ }^{63}$. La Corte ha señalado que las garantías con las que se ha de operar cualquier procedimiento administrativo son extensibles también a la relación y procedimiento de interlocución entre el migrante y la Administración de conformidad con el sometimiento de la Administración al derecho. La resolución administrativa que afecte a la presencia en dicho país y conlleve una orden de expulsión o algún tipo de privación temporal de libertad, como consecuencia de su estancia o presencia no legal en el territorio del Estado, será susceptible de recurso ante el órgano jurisdiccional competente. Esta resolución administrativa deberá ser motivada y debidamente fundamentada en derecho y siempre susceptible de recurso ante un órgano jurisdiccional que lo resuelva y descarte la arbitrariedad de la Administración en la resolución dictada.

La persona migrante en su relación con la Administración de justicia puede encontrarse en la condición de justiciable o de víctima de un hecho delictivo, por lo que atendiendo a su situación de vulnerabilidad precisará de una serie de garantías específicas ante los tribunales de justicia para superar esa posición inicial de debilidad. Es por esta razón que los Estados han de adoptar las medidas precisas que le permitan al migrante en su relación con la Administración de justicia superar el desconocimiento del idioma, del derecho procesal que regule el procedimiento específico en el que se encuentre como parte y la ausencia de recursos económicos que le permitan disponer de asistencia legal. La jurisprudencia de la Corte se ha hecho eco de la necesidad, por tanto, de que los Estados prevean un sistema de asistencia gratuita frente al que se encuentren profesionales del derecho con conocimiento

${ }^{62}$ Caso de personas dominicanas y haitianas expulsadas Vs. República Dominicana. Sentencia de 28 de agosto de 2014.

${ }^{63}$ Caso personas dominicanas y haitianas expulsadas Vs. República Dominicana. Sentencia de 28 de agosto de 2014 . 
especializado en la materia de extranjería. Ante el riesgo de sufrir indefensión frente a la Administración de justicia corresponderá a los Colegios de Abogados y a las «defensorías» prestar la asistencia legal necesaria a los migrantes, al objeto de hacer efectivo el derecho al debido proceso, más allá de su reconocimiento genérico en tratados internacionales o Constituciones nacionales.

Por tanto, junto al marco internacional y constitucional interno se requiere la existencia de normativa específica que se vea implementada con «buenas prácticas « a desarrollar por la Administración Pública competente en extranjería, así como por los órganos jurisdiccionales en su relación con los migrantes. Es de vital importancia para la Corte que las normas en materia de extranjería como las normas procesales contemplen todas las garantías y cautelas que permitan la efectividad real de los derechos del migrante ante los poderes públicos.

Por lo que respecta a los migrantes en situación irregular, hemos de señalar que dentro del estricto respeto de los derechos humanos, la Corte ha señalado que el Estado podrá otorgar un tratamiento diferenciado a los migrantes que se encuentren debidamente documentados y por tanto en una situación regular, en relación con los migrantes indocumentados, o bien entre migrantes y nacionales. Pero este tratamiento diverso siempre tiene que tener una justificación razonable, objetiva y proporcional y no lesionar en ningún caso los derechos humanos de los migrantes. En este sentido se debe recordar que «el deber de respetar y garantizar el principio de la igualdad ante la ley y no discriminación es independiente del estatus migratorio de una persona en un Estado $\rangle^{64}$. En relación con este ámbito la Corte ha recogido la obligación de no introducir en su ordenamiento jurídico regulaciones discriminatorias, «eliminar las regulaciones de carácter discriminatorio si las hubiere, combatir las prácticas de este carácter y establecer normas y otras medidas que reconozcan y aseguren la efectiva igualdad ante la ley de todas las personas $\rangle^{65}$.

Cuando se trate de migrantes indocumentados o que se encuentren en una situación de irregularidad sobrevenida, su situación inicial de vulnerabilidad se ve acrecentada por estar expuestos a las violaciones potenciales de sus derechos, que pueden derivar en un nivel elevado de desprotección. Además se ha de tener en cuenta las dificultades para acceder a los recursos públicos, por la ignorancia de su estatuto jurídico y, por tanto, de las condiciones en las que puede llevar a cabo su existencia en dicho país. Ante esta situación, la Corte recuerda que el marco internacional de referencia integrado por el Derecho Internacional de los Derechos Humanos opera con carácter general

${ }^{64}$ Caso personas dominicanas y haitianas expulsadas Vs. República Dominicana. Sentencia de 28 de agosto de 2014.

${ }^{65}$ Caso Vélez Loor Vs. Panamá. Sentencia de 23 de noviembre de 2010. 
cómo un mínimo fundamento de su posición jurídica y es por esta razón que ha de ser observado por todos los Estados.

En concreto y respecto de la realización de actividades laborales por parte de los migrantes en situación irregular, la Corte ha indicado la necesidad de preservar un conjunto de derechos de los mismos, ya que se ha constatado en numerosas ocasiones la falta de reconocimiento a los trabajadores migrantes indocumentados de los derechos laborales, con retribución inferior a la que les correspondería, despido por formar parte de sindicatos, recibir amenazas de deportación, etc. La vulnerabilidad de su situación se acrecienta ante las dificultades de acceder a la Administración de justicia en demanda de sus derechos, por lo que se debe facilitar el acceso a los tribunales de los trabajadores migrantes en situación irregular al objeto de hacer valer el ejercicio efectivo de sus derechos ${ }^{66}$.

La conexión entre el derecho a la vida y la salud con la integridad humana del migrante ha sido proclamada por la Corte que ha reconocido la obligación de los Estados de prestar atención médica sin discriminación a las personas migrantes, y con especial relevancia en los casos de emergencias que deben prestarse también a los migrantes en situación irregular ${ }^{67}$.

Especial consideración ha hecho la Corte respecto de la privación de libertad de migrantes por su condición de irregular. La vulnerabilidad de las personas migrantes en situación irregular que son privadas de libertad en centros penitenciarios en los que son recluidas con personas procesadas y/o sancionadas por la comisión de delitos, se puede ver acrecentada cuando pueden correr el riesgo de sufrir tratos abusivos y desprotección. Para evitar dicha vulnerabilidad, la Corte ha invocado la Convención para recoger la necesidad de que los Estados se abstengan de llevar a cabo actuaciones que propicien dicha vulnerabilidad y deben de adoptar, «cuando sea pertinente, medias necesarias y razonables para prevenir o proteger los derechos de quienes se encuentren en tal situación ${ }^{68}$. De tal forma que no basta con la observancia y respeto del principio de legalidad sino que los principios y medidas del ordenamiento interno deben ser también compatibles con la Convención ${ }^{69}$.

${ }^{66}$ Opinión Consultiva OC-21/2014. Derechos y garantías de niñas y niños en el contexto de la migración y/o en necesidad de protección internacional. Decisión de 19 de agosto de 2014.

${ }^{67}$ Caso Nadege Dorzema y otros Vs. República Dominicana. Sentencia de 24 de octubre de 2012.

${ }^{68}$ Caso personas dominicanas y haitianas expulsadas Vs. República Dominicana. Sentencia de 28 de agosto de 2014.

${ }^{69}$ Opinión Consultiva OC-21/14. Derechos y garantías de niñas y niños en el contexto de la migración y/o en necesidad de protección internacional. Decisión de 19 de agosto de 2014. 
Cuando los ordenamientos jurídicos de los Estados contemplen la posibilidad de la privación de libertad del migrante en situación irregular, se deben extremar las cautelas en la adopción de esta medida ${ }^{70}$, llevar un registro de los allí internados, así como supervisar las condiciones de los centros y espacios de alojamiento de aquéllos. En atención al riesgo que pueden correr los inmigrantes privados de libertad, como consecuencia de su condición de migrante incurso en algún procedimiento en la materia, se ha señalado la «necesidad» de que permanezcan en dependencias especificas destinadas a tal fin, diferentes de las que ocupen personas acusadas o condenadas por delitos penales y en ningún caso en centros penitenciarios ${ }^{71}$. Por tanto, la privación de libertad del migrante derivada exclusivamente de su situación irregular nunca tendrá carácter punitivo, deberá previamente estar prevista en la norma y aplicarse solo cuando sea estrictamente necesario y no baste con otras actuaciones previstas en el ordenamiento. Dicha privación de libertad debe ajustarse estrictamente a lo que la Convención Americana y la legislación interna establezca al efecto, siempre y cuando ésta sea compatible con la Convención ${ }^{72}$.

La duración de la privación de libertad deberá estar prevista en la norma correspondiente, inclusive la que se lleve a cabo con meros fines de identificación, con «un plazo máximo de retención, que en ningún caso podrá ser indefinido, ni tener una duración excesiva $\rangle^{73}$ y aplicarse por el mínimo tiempo posible. En consecuencia, se considerará arbitraria toda orden de detención que carezca de fundamentación jurídica y motivación en atención a las circunstancias particulares que concurran, pues en ningún caso se podrá adoptar aquélla de forma automática de la persona migrante ${ }^{74}$.

La persona migrante detenida debe ser informada con precisión e inmediatez de los cargos que se hubieren formulado en su contra así como de los motivos por los que procedería la expulsión o deportación. Para garantizar el derecho al proceso debido, el migrante privado de libertad desde que se produzca la detención tiene derecho a establecer contacto con abogado, familiares o funcionario consular ${ }^{75}$ para comunicar esta situación ${ }^{76}$. Como

70 Caso Vélez Loor Vs. Panamá. Sentencia de 23 de noviembre de 2010.

${ }^{71}$ Caso Vélez Loor Vs. Panamá. Sentencia de 23 de noviembre de 2010.

72 Opinión Consultiva OC-21/14. Derechos y garantías de niñas y niños en el contexto de la migración y/o en necesidad de protección internacional. Decisión de 19 de agosto de 2014.

${ }^{73}$ Naciones Unidas. Grupo de Trabajo sobre la Detención Arbitraria. Informe del Grupo. Anexo II. Deliberación No ${ }^{\circ}$. 5. Situación relativa a los inmigrantes o a los solicitantes de asilo, 1999, E/CN. 4/2000/4, principio 7.

${ }^{74}$ Caso de personas dominicanas y haitianas expulsadas Vs. República Dominicana. Sentencia de 28 de agosto de 2014.

75 Opinión Consultiva OC-16/99 del 1 de octubre de 1999. El derecho a la Información sobre la Asistencia Consular en el Marco de las Garantías del debido proceso legal.

${ }^{76}$ Caso Tibi Vs. Ecuador. Sentencia de 7 de septiembre de 2004. 
consecuencia del sacrificio que conlleva la restricción del derecho a la libertad en estos procedimientos «la asistencia jurídica gratuita se vuelve un imperativo de la justicia» ${ }^{77}$.

Respecto del menor migrante no acompañado se han establecido determinadas pautas que deben observarse como buenas prácticas para la salvaguarda de los derechos del menor. Entre otras, la Corte se ha hecho eco de las siguientes: el tratamiento acorde con la condición de menor, en atención a despejar la duda sobre la edad, evaluación y determinación de la misma, la determinación de si se encuentra acompañado o separado, la determinación de la nacionalidad o en su caso de su condición de apátrida, la obtención de información respecto de los motivos de su salida del país de origen, de su separación familiar así como, cuando sea necesario y pertinente, la adopción de medidas de protección especial ${ }^{78}$.

Ahora bien, cuando el menor haya sido víctima de trata o potencialmente esté en ese riesgo, dada la extrema vulnerabilidad del mismo, los Estados deben adoptar cuantas medidas sean pertinentes para protegerles contra un nuevo riesgo de victimización y prestarles todo tipo de asistencia desde la estrictamente jurídica a la médica o psicológica, sin olvidar aquellas otras que puedan contribuir a su educación o capacitación.

La Corte ha hecho hincapié en el principio del interés superior del menor, motivación esta por la que no debe privarse de libertad como regla general, a los menores no acompañados o separados de su familia. La privación de libertad no podrá justificarse solamente porque el menor esté solo o separado de su familia, ni por su condición de inmigrante o no residente.

En cuanto a las situaciones de apatridia ${ }^{79}$, más allá de las previsiones contenidas en la Convención para Reducir los Casos de Apatridia de 1961, se debe recordar como la Convención Americana recoge el derecho a la nacionalidad en una doble consideración, esto es, por lo que respecta al derecho a disponer de una nacionalidad, desde la perspectiva de «dotar al individuo de un mínimo de amparo jurídico en el conjunto de relaciones, al establecer su vinculación con un Estado determinado» y, por otro lado, a su no privación de nacionalidad.

En este sentido, la determinación de la nacionalidad resulta relevante a los efectos de clarificar el derecho de una persona a permanecer en un país

77 Caso Vélez Loor Vs. Panamá. Sentencia de 23 de noviembre de 2010.

${ }^{78}$ Opinión Consultiva OC-21/14. Derechos y garantías de niñas y niños en el contexto de la migración y/o en necesidad de protección internacional. Decisión de 19 de agosto de 2014.

${ }^{79}$ Un apátrida es «toda persona que no sea considerada como nacional suyo por ningún Estado, conforme a su legislación». Convención sobre el Estatuto de los Apátridas, adoptada el 28 de septiembre de 1954. 
mientras se sustancia el procedimiento de expulsión, o en relación con la identificación del país o países respecto de los que se alega poseer un temor fundado de ser perseguida, al objeto de la tramitación de alguna fórmula de protección internacional. Corresponde a los Estados establecer con claridad y objetividad los requisitos pertinentes para la obtención de la nacionalidad, sin que la condición de migrante pueda constituir una justificación para privarle del derecho a la nacionalidad.

Puesto que la potestad del reconocimiento de la nacionalidad corresponde a los Estados, lógicamente el establecimiento de las condiciones y procedimientos para su adquisición quedarán reservados al derecho interno. Ahora bien, por imperativo del artículo 20 de la Convención ha señalado la Corte que «es necesario conjugar armoniosamente», de un lado, la competencia estatal sobre la regulación y determinación de la nacionalidad, y por otro, las disposiciones de derecho internacional que «limitan, de alguna forma, esta facultad (...) de los Estados en razón de exigencias de la protección internacional $»^{80}$.

De por otra parte, el derecho a la nacionalidad comprende la obligación de los Estados de «proteger al individuo contra la privación de su nacionalidad en forma arbitraria», por lo que las normas que regulen la adquisición de la misma no deben reconocer margen de discrecionalidad amplio a los Estados para su reconocimiento, evitándose así la aparición de actos discriminatorios. Esta doble vertiente sobre el derecho a tener una nacionalidad ha sido enunciada por la Corte, de un lado, para dotar al individuo de un mínimo de amparo jurídico en el conjunto de relaciones al establecer su vinculación con un Estado determinado y, por otro lado, para proteger al individuo contra la privación de su nacionalidad de forma arbitraria, con la consecuente indefensión que le llevaría aparejada la ausencia del resto de derechos civiles y políticos.

En suma, constituye una obligación de los Estados la identificación, prevención y reducción de la apatridia dada la extrema vulnerabilidad que conlleva esta condición y, por ello, les corresponde dotar a las personas de un estatus jurídico en el que se comprenda la titularidad de derechos civiles y políticos vinculados a la disposición de una nacionalidad ${ }^{81}$.

\section{EL DERECHO A CONOCER LA VERDAD.}

En el contexto de los conflictos internos habidos en el área regional de aplicación de la Convención Americana, las desapariciones forzadas han

80 Opinión Consultiva OC-4/84 de 19 de enero de 1984.

${ }^{81}$ Caso de las niñas Yean y Bosico Vs. República Dominicana. Sentencia de 8 de septiembre de 2005 . 
dado lugar a diversas denuncias, recursos y pronunciamientos de la Corte. Para realizar una breve aproximación al tratamiento de las desapariciones forzadas hay que recordar la jurisprudencia de la Corte sobre la privación de la libertad, la prohibición de torturas, tratos inhumanos y degradantes, así como la existencia de garantías jurídicas recogidas en la Convención ante las restricciones de la libertad ${ }^{82}$.

Con carácter inicial hemos de recordar como todos los Estados tienen el derecho y el deber de garantizar su propia seguridad, de tal modo que aun cuando se haya de hacer frente por la sociedad a infracciones del orden público y por la comisión de determinados hechos puedan ser condenados los autores de aquellos delitos, «no cabe admitir que el poder pueda ejercerse sin límite alguno o que el Estado pueda valerse de cualquier procedimiento para alcanzar su objetivo, sin sujeción al derecho o a la moral $»^{83}$, de tal modo que el respeto a la dignidad humana y a los derechos fundamentales constituye un límite infranqueable para los Estados.

Pues bien, ante la privación de libertad, se impone la exigencia contenida en la Convención del debido respeto a la dignidad de quien sufre dicha privación (art. 5.2). Igualmente la privación de libertad solo se puede acordar dentro de la legalidad de los supuestos en los que esté prevista, que en ningún caso puede ser arbitraria (art. 7). En el supuesto de sufrir detención o retención se debe informar a la mayor brevedad de los cargos que se le imputan y su conducción ante el juez para que resuelva sobre «la legalidad de su arresto o detención y ordene su libertad si el arresto o la detención fueran ilegales«.

La Convención recoge como garantía jurídica esencial el derecho de toda persona «a ser oída, con las debidas garantías y dentro de un plazo razonable, por un juez o tribunal competente, independiente e imparcial» (art. 8.1) que se ve completado con el «derecho a un recurso sencillo y rápido o a cualquier otro recurso efectivo ante los jueces o tribunales competentes, que la ampare contra actos que violen sus derechos fundamentales reconocidos por la Constitución, la ley o la presente Convención, aun cuando tal violación sea cometida por personas que actúen en ejercicio de sus funciones oficiales» (art. 25).

La Corte se ha pronunciado sobre el carácter absoluto e inderogable de la prohibición de tortura ${ }^{84}$, penas o tratos crueles, inhumanos o degradantes incluso cuando concurran situaciones de conflicto armado, terrorismo, situaciones de emergencia o suspensión de garantías constitucionales. Es por ello que cuando los Estados impongan sanciones deben atender a la proporcionalidad

${ }^{82}$ En el ámbito del Consejo de Europa resulta de gran interés, J. M. López Ulla, Derecho a la verdad y desapariciones forzadas (Thomson Reuters-Aranzadi, Cizur Menor, 2015).

${ }^{83}$ Caso Neira Alegría y otros Vs. Perú. Sentencia de 19 de enero de 1995.

${ }^{84}$ Caso Cantoral Benavides Vs. Perú. Sentencia de 18 de agosto de 2000. 
de las penas, de tal modo que la imposición de penas «radicalmente desproporcionadas (...) atroces en sí mismas, se encuentran bajo el ámbito de aplicación de las cláusulas que contienen la prohibición de la tortura y los tratos crueles, inhumanos y degradantes $\rangle^{85}$.

En particular, constituye una obligación ineludible de los Estados garantizar los derechos de las personas privadas de libertad. En este sentido la Corte ha concretado a través de su jurisprudencia las condiciones generales que han de regir la privación de libertad de conformidad con el Derecho Internacional de los Derechos Humanos, con garantía de que «la manera y el método de privación de libertad no excedan el nivel inevitable de sufrimiento inherente a la detención ${ }^{86}$, así como las cautelas y garantías que han de observarse respecto de personas pertenecientes a grupos en situación de vulneración de sus derechos privados de libertad.

$\mathrm{Al}$ objeto de garantizar un trato digno y humano se debe llevar un registro de todas las personas detenidas, su identidad, los motivos de su detención, autoridad competente que lo dispuso, fecha de ingreso y de salida. La incomunicación constituirá una medida excepcional únicamente motivada por el objetivo de «asegurar los resultados de una investigación y que sólo puede aplicarse si es decretada de acuerdo con las condiciones establecidas« previamente en la ley.

En este sentido, la desaparición forzada ha sido considerada por la Corte, a tenor de lo preceptuado en el artículo 5 de la Convención, como una vulneración de la integridad personal de la víctima ${ }^{87}$, ya que toda persona tiene reconocido el derecho al respeto de su integridad y, por ello, «no podrá ser sometido a torturas, ni a penas o tratos crueles, inhumanos o degradantes. Toda persona privada de libertad será tratada con el respeto debido a la dignidad inherente al ser humano».

La obligación para todos los Estados parte derivada del art. 1 de la Convención implica según la jurisprudencia de la Corte que «siempre que una persona es privada de libertad en un estado de salud normal y posteriormente aparece con afectaciones a su salud, corresponde al Estado proveer una explicación satisfactoria y convincente de esa situación y desvirtuar las alegaciones sobre su responsabilidad, mediante elementos probatorios adecuados». Corresponde por tanto a los Estado la obligación de investigar las denuncias sobre violaciones de derechos humanos que se formulen, así como ofrecer una explicación satisfactoria que «pueda refutar las pretensiones» de quienes formularon las demandas. En ocasiones y en ausencia de explicación podrá

${ }^{85}$ Caso Mendoza y otros Vs. Argentina. Sentencia de 14 de mayo de 2013.

${ }^{86}$ Caso Mendoza y otros Vs. Argentina. Sentencia de 14 de mayo de 2013.

${ }^{87}$ Caso Gudiel Álvarez y otros («Diario Militar») Vs. Guatemala. Sentencia de 20 de noviembre de 2012. 
presumirse la responsabilidad estatal «por las lesiones que exhibe una persona que ha estado bajo la custodia de agentes estatales $\rangle^{88}$.

Respecto al tratamiento que se debe conceder a las denuncias de torturas que se formulen existe una clara obligación por parte de los Estado de investigar los posibles actos de tortura de conformidad con el artículo 5.1 y 2 de la Convención Americana. Al amparo del artículo 8 de la Convención a las víctimas de violaciones de derechos humanos, o sus familiares, se les reconoce el derecho a intervenir en los procedimientos pertinentes de conformidad con las reglas del debido proceso ${ }^{89}$.

Pues bien con esta interpretación de la Convención ya reiterada por la Corte, se ha evolucionado hacia la configuración jurisprudencial del denominado derecho a la verdad. Constituye uno de los elementos más relevantes de la jurisprudencia de la Corte en el ámbito de los derechos humanos el derecho de las víctimas a «conocer la verdad sobre las circunstancias de la desaparición forzada, la evolución y resultados de la investigación y la suerte de la persona desaparecida ${ }^{90}$. Así, la violación del derecho a conocer la verdad de los familiares de las victimas desaparecidas conllevara, como consecuencia derivada de este incumplimiento por parte de los Estados, una sentencia condenatoria de éstos.

La construcción jurisprudencial de la Corte ha llevado al reconocimiento en un primer pronunciamiento de la existencia de un «derecho de los familiares de la víctima de conocer cuál fue el destino de ésta y, en su caso, dónde se encuentran sus restos ${ }^{91}$. La desaparición forzada constituye una violación de derechos humanos con tres elementos que la caracterizan según la Corte, de una lado, la privación de la libertad, seguida de una intervención directa de agentes «estatales o la aquiescencia de estos», y por último, «la negativa de reconocer la detención y la de revelar la suerte o el paradero de la persona interesada». Con posterioridad dicho reconocimiento se ha concretado en su caracterización con su consideración como pluriofensiva y su naturaleza permanente o continuada, ya que tiene el comienzo con la privación de la libertad, se prolonga con la ausencia de información respecto del destino del desaparecido y «permanece» en tanto no se tenga conocimiento del paradero de la persona desaparecida o puedan ser hallados los restos que permitan acreditar su identidad. De tal modo que concurre en la desaparición forzada una diversidad de conductas cuyo fin no es otro que la vulneración mientras

${ }^{88}$ Caso Hermanos Landaeta Mejías y otros Vs. Venezuela. Sentencia de 27 de agosto de 2014.

${ }^{89}$ Caso Vera Vera y otra Vs. Ecuador. Sentencia de 19 de mayo de 2011.

90 Art. 24.2 de la Convención Internacional para la Protección de Todas las Personas contra las Desapariciones Forzadas

${ }^{91}$ Caso Velásquez Rodríguez Vs. Honduras. 
subsista la situación, de un conjunto diverso de bienes protegidos ${ }^{92}$ durante el tiempo que, dentro del derecho de la víctima o de sus familiares de obtener del Estado y sus órganos competentes, se produce «el esclarecimiento de los hechos violatorios y las responsabilidades correspondientes», por medio de la investigación y el enjuiciamiento de los hechos a tenor de lo preceptuado en los ya citados artículos 8 y 25.1 de la Convención ${ }^{93}$.

En sucesivos pronunciamientos de la Corte se ha perfilado el alcance de este derecho que parte de la consideración de víctima de los familiares de quienes hubieren sido objeto de desapariciones forzadas y, por tanto, son titulares del derecho a que los hechos que dieron lugar a las desapariciones sean investigados, conocer el destino de los desaparecidos, el lugar donde se encuentran sus restos y sus responsables sean procesados y, en su caso, sancionados. Es en este sentido en el que la Corte ha afirmado que el derecho a la verdad «se enmarca en el derecho de acceso a la justicia». Por cuanto supone una exigencia para los aparatos del Estado dicha investigación, la Corte ha considerado el derecho a la verdad como «una forma de reparación«, en el contexto de un Estado democrático de tal modo que ésta «es una justa expectativa que el Estado debe satisfacer, por un lado, con la divulgación pública de los resultados de los procesos penales e investigación y, por otro, con la sanción de los responsables. La consecuencia lógica que se extrae de esta obligación de los Estados es la posibilidad de crear Comisiones de la Verdad con el objeto de contribuir a la memoria histórica, al esclarecimiento de los hechos y «la determinación de responsabilidades institucionales, sociales y políticas en determinados períodos históricos de una sociedad $\rangle^{94}$.

En sentido contrario a las obligaciones que se derivan de la Convención se ha señalado que la amnistía, en la medida en que imposibilita la investigación y sanción de los responsables de las violaciones graves de derechos humanos en general y en particular, del acceso de las víctimas y familiares a conocer la verdad de lo sucedido, así como a obtener las reparaciones pertinentes, constituye una violación de la Convención además de contribuir a la impunidad con grave deterioro del Estado de derecho ${ }^{95}$.

Otro aspecto relevante que presenta la jurisprudencia de la Corte es el relativo a precisar los límites que permitan configurar la desaparición forzada de forma autónoma dentro de las violaciones de derechos humanos. En efecto, a través de los pronunciamientos de aquélla, se pueden concretar las diferencias que concurren en los supuestos de desapariciones frente a las

${ }^{92}$ Caso Comunidad Campesina de Santa Bárbara Vs. Perú. Sentencia de 1 de septiembre de 2015.

${ }_{93}$ Entre otros Caso Gelman Vs. Uruguay. Sentencia de 24 de febrero de 2011.

${ }^{94}$ Caso Anualdo Castro Vs. Perú. Sentencia de 22 de septiembre de 2009.

95 Caso Gelman Vs. Uruguay. Sentencia de 24 de febrero de 2011. 
ejecuciones extrajudiciales, en tanto que la situación de los desaparecidos se prolonga en el tiempo hasta que los restos de las víctimas sean localizados y comprende la obligación por parte del Estado y sus autoridades de llevar a cabo la tipificación, investigación y sanción de estas conductas. La responsabilidad del Estado se ve incrementada en la medida en que con el transcurso del tiempo no se realizan las averiguaciones pertinentes para el esclarecimiento de los hechos y la localización del paradero de las personas desaparecidas $^{96}$.

La Corte ha señalado que «una de las características de la desaparición forzada, a diferencia de la ejecución extrajudicial, es que conlleva la negativa del Estado de reconocer que la víctima está bajo su control y de proporcionar información al respecto, con el propósito de generar incertidumbre acerca de su paradero, vida o muerte, de provocar intimidación y presión de derechos». Es más, en la calificación de los hechos como desaparición forzada incorpora la Corte el hecho de que producida la muerte de las víctimas, se adoptasen medidas expresamente encaminadas a la ocultación de lo sucedido con la intencionalidad de borrar el rastro de los cuerpos e impedir su identificación, destino y paradero ${ }^{97}$.

${ }^{96}$ Caso Comunidad Campesina de Santa Bárbara Vs. Perú. Sentencia de 21 de noviembre de 2016.

${ }_{97}$ Caso Miembros de la Aldea Chichupac y Comunidades vecinales del municipio de Rabinal Vs. Guatemala. Sentencia de 30 de noviembre de 2016. 